IZA DP No. 8394

One-Child Policy and the Rise of Man-Made Twins

Wei Huang

Xiaoyan Lei

Yaohui Zhao

August 2014

Forschungsinstitut zur Zukunft der Arbeit Institute for the Study of Labor 


\title{
One-Child Policy and the Rise of Man-Made Twins
}

\author{
Wei Huang \\ Harvard University and IZA \\ Xiaoyan Lei \\ CCER, NSD, Peking University and IZA \\ Yaohui Zhao \\ CCER, NSD, Peking University and IZA
}
Discussion Paper No. 8394
August 2014

IZA
P.O. Box 7240
53072 Bonn
Germany

Phone: +49-228-3894-0

Fax: +49-228-3894-180

E-mail: iza@iza.org

Any opinions expressed here are those of the author(s) and not those of IZA. Research published in this series may include views on policy, but the institute itself takes no institutional policy positions. The IZA research network is committed to the IZA Guiding Principles of Research Integrity.

The Institute for the Study of Labor (IZA) in Bonn is a local and virtual international research center and a place of communication between science, politics and business. IZA is an independent nonprofit organization supported by Deutsche Post Foundation. The center is associated with the University of Bonn and offers a stimulating research environment through its international network, workshops and conferences, data service, project support, research visits and doctoral program. IZA engages in (i) original and internationally competitive research in all fields of labor economics, (ii) development of policy concepts, and (iii) dissemination of research results and concepts to the interested public.

IZA Discussion Papers often represent preliminary work and are circulated to encourage discussion. Citation of such a paper should account for its provisional character. A revised version may be available directly from the author. 
IZA Discussion Paper No. 8394

August 2014

\section{ABSTRACT}

\section{One-Child Policy and the Rise of Man-Made Twins*}

This paper investigates how people respond to the distorted incentives of One-Child Policy by examining its impact on twin births in China. The analysis using population census data shows that the One-Child Policy accounts for more than one-third of the increase in twin births since the 1970s. Further investigation finds that the One-Child Policy is associated with a larger birth gap of twins with prior births and greater height difference between twins. These findings suggest that the increase in twin births can partly be explained by parents registering single children as twins in order to avoid the policy violation punishment.

JEL Classification: J08, J11, J13

Keywords: $\quad$ twins, one-child policy, China

Corresponding author:

Wei Huang

Department of Economics

Harvard University

1805 Cambridge Street

Cambridge, MA 02138

USA

E-mail: weihuang@fas.harvard.edu

\footnotetext{
*We thank Gary Becker, Amitabh Chandra, David Cutler, Avraham Ebenstein, Richard Freeman, Edward Glaeser, Claudia Goldin, James Heckman, Lawrence Katz, Mark Rosenzweig, John Strauss, T. Paul Schultz, and David Wise for their helpful suggestions. We also thank the discussants at the PAA conference, the China Meeting of the Econometric Society, and the CGEB/LAEF Conference on Economics and Demography for their comments. All errors are ours.
} 
"One is too few," said a woman (in China) waiting at the hospital. "People want to have a second child."-Elizabeth Grether, ABC News, August 3, 2011

\section{Introduction}

Since Rosenzweig and Wolpin (1980a, 1980b), an established strand of economics literature has used samples of twins to deal with biases from unobserved factors, particularly in estimating educational returns and effects of family size (Ashenfelter and Krueger 1994; Ashenfelter and Rouse 1998; Rosenzweig and Wolpin 2000; Behrman and Rosenzweig 2002; Black et al. 2007; Royer 2009; Angrist and Evans 1998; Angrist et al. 2010; Ponczek and Souza 2012). This methodology has been further developed and followed by studies in various contexts, including developing countries such as China (Chew et al. 2010; Zhang et al. 2007; Li et al. 2007, 2011, 2012, 2013; Rosenzweig et al. 2009; Rosenzweig and Zhang 2012). These studies usually assume that twins are born randomly across the population conditional on some observed biological factors, such as mother's age at childbirth and ethnicity. This somewhat ad hoc assumption implies that twins are not expected before pregnancy and their births may not be manipulated.

No previous research has considered seriously the possibility that twin births could be manipulated in response to the distorted incentives imposed by relevant fertility policies. For the first time, our paper investigates the impact of fertility policy on twin births in China to examine the behavioral responses to the distorted incentives of China's One-Child Policy. The importance of this issue lies not only in the external validity of assuming twin births as random in the 
Chinese context, but also in better understanding behavioral responses toward public policies in general.

We look at China because its fertility policy provides a unique opportunity to answer the question. In the 1970s, China started a series of measures to curb population growth. The One-Child Policy was formally conceived in 1979 and firmly established across the country in 1980 (Croll et al. 1985; Banister 1987; Greenlaugh 1986, 1992; Qian 2009). Meanwhile, twin births as reported in population censuses more than doubled between the late 1960s and the early 2000s, as shown in Figure 1, from 3.5 to 7.5 per thousand births. The rate of increase of twin births was greater after 1980, when the One-Child Policy was fully implemented. ${ }^{1}$

[Figure 1 about here]

This paper argues that the One-Child Policy has contributed to the increase in twin births since the 1970s. First, the One-Child Policy distorted the incentives for individuals to give birth to twins. As the policy's name suggests, one couple is allowed to have only one child, although there are a few exceptions. ${ }^{2}$ If a mother delivers an illegal birth, the household may face heavy

${ }^{1}$ However, the pattern of increasing twins in China is not unique and the rate of twin births is heterogeneous across different populations. For example, the rate of twin births increased from 18.9 to 33.3 per thousand births from 1980 to 2009 in the United States (Martin et al. 2012). It is difficult to come to any conclusion before serious analysis.

${ }^{2}$ The exemptions include the following: some rural couples, if their first child is a girl; ethnic minorities; cases when the first child is disabled or adopted; parents without any siblings themselves; disabled soldiers; couples who have lived in the mountains or special areas for a long time; and parents in special or dangerous occupations, such as coal mining or fishing, who have only a girl child. 
punishment from the government, such as regulatory policy fines or even job loss if they are working in the state sector. Such a policy provides a strong incentive for parents to have twins, if they can, as it is a legal way to have more than one child.

Second, individuals may "make" twins intentionally. One option is to take fertility drugs. Fertility drugs can induce ovulation; thus, they are usually used to treat infertility. But as $\mathrm{ABC}$ News reported, women sometimes intentionally take fertility drugs to give birth to twins. ${ }^{3,4}$ For those who fail in having a twin birth, an alternative option is to report fake twins, i.e., to register two consecutive siblings as twins. ${ }^{5}$ For example, an administrative department in Yunnan province found and identified 700 pairs of fake twins in 342 villages in 2000. More surprisingly, among 23 pairs of twins reported born in 1999, 18 were identified as fake twins. ${ }^{6}$

Taking advantage of the timing and geographical variation of policy violation fines, this paper first investigates the extent to which the One-Child Policy affects twin births in China. The estimates suggest that the One-Child Policy accounts for at least one-third of the increase in twin births since the 1970s and such policy-associated twins are more likely to be found in rural areas

${ }^{3}$ Because of the lack of stringent administration, these drugs are easily accessible, for example through online pharmacies and private hospitals.

4 The source for the news is:

http://abcnews.go.com/Health/chinese-women-fertility-drugs-bypass-child-policy/story?id=1421 9173

5 An example (in Chinese):

http://www.wuhan.jcy.gov.cn/yasf/200905/t20090519_221490.html

${ }^{6}$ Source (in Chinese): http://www.people.com.cn/GB/channel1/13/20000728/163617.html. 
and for observed second births. ${ }^{7}$ Because of the potential endogeneity of the policy fines and that the One-Child Policy mainly focused on the Han ethnicity, we conduct an alternative set of regressions comparing the differential twin birthrates between Han and minority Chinese before and after the One-Child Policy, which yields consistent and robust results.

We then investigate further whether people obtain "man-made" twins through taking fertility drugs or through registering single children as twins. Identifying either or both of the mechanisms will further support the impact of the One-Child Policy on twin births. We focus on the observed second births and find that the birth gap between the first birth and the observed second twin birth is 0.08 years longer relative to an observed second single delivery after the One-Child Policy was introduced. In addition, our investigation of the twins' height difference finds that One-Child Policy fines are positively correlated with the height difference between twins, for both same gender and different gender twins. These findings are consistent with the hypothesis that the One-Child Policy incentivizes parents to report non-twin children as twins. ${ }^{8}$ The results allude to the importance of carefully screening twins with observable characteristics when analyzing Chinese data sets of twins. ${ }^{9}$

\footnotetext{
${ }^{7}$ The observed second births may not be real second births because the parents may report fake twins. As discussed later, the parents possibly report the second birth child and the third birth child together as twins. Therefore, these twins are observed as second births.

${ }^{8}$ It is worth noting that the results do not rule out the possibility that couples may take fertility drugs to have twins.

${ }^{9}$ For example, Zhang et al. (2007), Li et al. (2012) and Rosenzweig and Zhang (2012) carefully examined the hair color, appearance, and so forth of twins.
} 
Therefore, this study finds a sizeable behavioral response from Chinese couples against the One-Child Policy from the angle of twin births, and provides evidence that twins may not be distributed randomly against the backdrop of the distorted fertility policy.

The structure of the paper is as follows. Section 2 introduces the data used in the study and provides background for the One-Child Policy. Section 3 uses census data to examine the impact of the One-Child Policy on twin births in China. Section 4 uses the China Health and Nutrition Survey (CHNS) data to differentiate two sources of twins by looking at the impact of the One-Child Policy on the birth gap between twins and other siblings as well as the height difference between twins. Section 5 concludes with a discussion of the findings and policy implications.

\section{Data}

\subsection{Census Data and Twins in China}

The data used in this study are from the 1982, 1990, and 2000 Population Censuses and the 2005 One-Percent Population Survey. All the data sets contain birth year, region of residence, type of residence, ${ }^{10}$ gender, ethnicity, education, and relation to the household head. The data sets after

${ }^{10}$ The 1990 Census does not provide the type of current residence; it provides information on whether the respondents lived in the same place five years ago and what the type of residence was then. Therefore, we constructed an indicator for current residence. First, we keep those who were in the same place. Then we calculate the proportion of people in the sample for each residence type five years ago. We use the residence type with the highest proportion as the type of current residence for the area. 
1982 also include month of birth. For women older than 15 , the data also provide information about their fertility history, including number of children ever born and number of living children.

For the analysis of twin births and family background, we first keep only those households with at least one child and with information available for the mother. We restrict the sample to those whose household heads and spouses are their first marriage and further restrict the sample to those households with equal numbers of reported living children, children ever born, and children observed in the survey. Doing so ensures that all the children in each household are born by the mother observed in the household and that the sample covers the information needed for the children. In case we miss children who have moved from the household, we further drop households with children over age 17 in the survey. We finally drop households where the mother's age at childbirth is either younger than 15 or older than 50 , as these subsamples may be too special or may contain recording errors. ${ }^{11}$

With all the restrictions stated above, twins are defined as children in the same household with the same birth year and birth month. ${ }^{12}$ The observations are at the birth level, so twins are treated as a single observation as they are in the same birth. Figure 1 plots the rate of twins by

\footnotetext{
11 We also drop data for Tibet.

12 Because the 1982 Census data do not have information on birth month, we define twins in that year as those children born in the same household with the same birth year only. Actually, the results are almost the same when we either drop the 1982 Census or define twins only using the year of birth in all data sets.
} 
year of birth between 1965 and 2005. The variation before 1970 and after 1990 is larger because of the smaller sample size. To achieve consistent and nationally representative estimates, we apply sampling weights throughout the analysis.

\subsection{The One-Child Policy}

Family planning policy appeared in the Constitution for the first time in 1978. It reappeared in more detail in the 1982 amended Constitution (Greenlaugh 1986, 1992; Wang 2012). Legal measures, such as monetary penalties and subsidies, have also ensured the effective enforcement of the One-Child Policy since 1979. Because of the heterogeneous regional development across China, Central Party Committee "Document 7" devolved responsibility from the central government to the local and provincial governments so that local conditions could be better addressed. Document 7 actually allowed for regional variation in family planning policies, such as the amounts for monetary penalties or subsidies (Greenlaugh 1986). As the population was still growing rapidly in the 1980 s, Chinese policy makers felt more compelled to constrain fertility and emphasized the importance of this policy in several documents. Local governments tightened enforcement by reducing land allotments, denying access to public services, and so on.

However, it is worthwhile to note that the One-Child Policy mainly focused on the Han ethnicity, the largest ethnicity in China with more than 90 percent of the population. Although local governments might have enacted different regulations for local minorities, these regulations were usually less restrictive compared with those for Han people. For example, regulations in Gansu province allow minority parents to have a second birth, which is not allowed for the 
Han. $^{13}$

The measure of the One-Child Policy in this study is the average monetary penalty rate for one unauthorized birth in the province-year panel from 1979 to 2000; the data are from Ebenstein (2010). ${ }^{14}$ The One-Child Policy regulatory fine (policy fine) is formulated in multiples of annual income (Ebenstein 2010; Wei 2011). Although the monetary penalty is only one aspect of the policy and the government may take other administrative actions, it is still a good quantitative measure because an increase in the fine is usually associated with other, stricter policies. Figure 2 shows the pattern of policy fines in 1980-2000 in each province.

[Figure 2 about here]

It is obvious that fines in different provinces generally follow different patterns, both in timing and in magnitude. For example, Liaoning province raised the fine from one year's income to five in 1992, while Guizhou raised the fine from two to five years of income in 1998 and Hunan from one to two years of income in 1989. The average level of the fine was higher in the 1990s than in the 1980s, which is consistent with stricter policy enforcement in the 1990s. The geographical and temporal variation helps us identify the impact of the One-Child Policy on the twin births in the following empirical analysis.

Since a period of approximately nine months is needed from the beginning of pregnancy until birth, parents' decision to have a child, if any, should be made close to a year in advance.

${ }^{13} \mathrm{http} / / /$ www.mjrkj.gov.cn/html/gs-law/17_31_12_360.html.

${ }^{14}$ Details on the construction of this variable can be found in Ebenstein (2010). 
For each birth, we construct a variable, policy fine rate, which is the weighted mean value of the fine rate in the 12 months just before the pregnancy in a given province. For example, if a child was born in Jiangxi province in September 1986, the mother is expected to have started her pregnancy in December 1985. The policy fine rate is then equal to the weighted mean value of the fine rate in Jiangxi province between December 1984 and November 1985, which equals $1 / 12$ ine $_{\text {jiangxi }}^{1984}+11 / 12$ Fine $_{\text {jiangxi }}^{1985}$. However, because the 1982 Census does not have birth month information, we simply assume the children surveyed in 1982 were born in June and conduct the same procedure as above.

It should be emphasized that more than 92 percent of the children surveyed in 1982 were born before 1979 when the One-Child Policy started, so the effective fine rate was zero for them. It is also noteworthy that the estimates do not rely on the One-Child Policy measure we constructed here. The results are consistent if we simply use the fine rate one year before the child was born. Since we have fine rate data from the start of the One-Child Policy until the year 2000, we drop the children born after 2001.

In matching the policy fine rate to the current local province, we assume that the observed children were born in the province where they reside at the time of the survey, which may not be true due to migration. Using census data after 1990 that contain information on place of birth, we found that 96.5 percent of the children live in the same province where they were born. Therefore, interprovincial migration should not be an issue of concern in the analysis.

Table 1 presents the summary statistics. Column 1 shows that the reported rate of twin births in the full sample is 5.8 per thousand births. We then divide the sample by the parents' 
ethnicity. ${ }^{15}$ The twin birthrate is 5.9 for the Han and 4.4 for the minority sample. The mean age of children in the sample is around eight and the mean age of the mother at childbirth is about 23 , for which only a small difference between Han and minorities is observed. More than half the births are first deliveries. A larger fraction of minority women have more than one birth, as they are less restricted by the One-Child Policy.

\section{[Table 1 about here]}

Table 2 compares twin birthrates before and after the One-Child Policy, by parents' ethnicity. For the Han ethnicity sample, the twin birthrate increased by 0.28 percentage points after the One-Child Policy (from 0.39 to 0.67 ), while that for the minority group only increased by 0.07 percentage points (from 0.38 to 0.45 ). Admittedly, the twin birthrate may be influenced by other factors, but this simple comparison suggests that the One-Child Policy may have potentially accounted for a large proportion of the growth rate of twin births.

[Table 2 about here]

\section{Empirical Results}

\subsection{Results Using One-Child Policy Fines}

To evaluate the effects of the One-Child Policy on the twin birthrate, we estimate the following equation:

$$
\text { (1) } \operatorname{Twin}_{i j k y}=\beta_{0}+\beta \text { Fine }_{j y m}+\theta X_{i j}+\delta_{k y}+\delta_{j}+\gamma_{j} \mathrm{~T}_{j}+\varepsilon_{i j}
$$

${ }^{15}$ For simplicity, throughout the paper, we define Han ethnicity as both parents being Han. 
where the dependent variable, $T w i n_{i j k y}$, denotes whether birth $i$ born in year $y$ and province $j$ is a twin birth in survey year $k$. Fine $e_{j y m}$ is the One-Child Policy fine rate defined above in province $j$ for children born in year $y$ and month $m$. The main coefficient of interest, $\beta$, gives the association of the One-Child Policy fines with the reported twin birthrate and is interpreted as the impact of the One-Child Policy. $\beta(s)$ are expected to be positive, which implies that the twin birthrates are higher in areas with more stricter One-Child Policy.

$X_{i j}$ is a set of covariates, including dummies for residence type (urban/rural), parents' ethnicity (both Han or either a minority), birth order, birth month, mother's education level, and mother's age at childbirth. $\delta_{k y}$ is a set of dummies for year of birth $y$, year of survey $k$, and their interaction. The interaction terms capture the age effects since parents may not report some children as twins at a very young age because the parents have not yet had another child to pair with the first child. $\delta_{j}$ and $T_{j}$ denote the province dummies and province-specific birth year linear trends, respectively.

The first three columns in Table 3 report the OLS estimates for $\beta$ in Equation (1) with standard errors clustered at the provincial level. Column 1 reports results for the full sample while columns 2 and 3 report results for the Han and minority samples, respectively. ${ }^{16}$ The results indicate that an increase equivalent to one year's income in the policy fine is associated with 0.067 percentage point increase in the twin birthrate among the whole sample. As expected,

16 All coefficients are interpreted as percentage points since the dependent variable has been multiplied by 100 to avoid too many zeros in the coefficients. 
both the association and significance survive in the sample for Han ethnicity but diminish in the sample for the minority group. Given that the policy fine rate increased from 0 to 1.4 after the One-Child Policy, the estimates in column 2 suggest that 36 percent $(=0.0717 * 1.4 / 0.276)$ of the increase in twins in the Han ethnicity sample can be attributed to the One-Child Policy. Note that the standard errors are clustered at the provincial level to allow for any correlation within each province, which, if not corrected, may underestimate the precision of our estimation.

\section{[Table 3 about here]}

Based on the above results, we further interact the policy fine with Han ethnicity and estimate the following equation:

(2) Twin $_{i j k y}=\beta_{0}+\beta_{1}\left(\right.$ Fine $_{j y m} \times$ Han $\left._{i}\right)+\beta_{2}$ Fine $_{j y m}+\theta X_{i j}+\delta_{k y}+\delta_{j}+\gamma_{j} \mathrm{~T}_{j}+\varepsilon_{i}$ where $\operatorname{Han}_{i}$ denotes whether both parents of birth $i$ are of Han ethnicity. All the other variables are defined in the same way as in Equation (1). Column 4 in Table 3 reports the estimates and clustered standard errors. Although the magnitude is slightly smaller than that in column 2 , the difference is insignificant, once again suggesting that the One-Child Policy plays an important role in affecting the rate of twin births in China.

Li et al. (2011) argue that spatial and temporal variation of the One-Child policy may be endogenous. They find that the policy fine increases with community wealth and local government's birth-control incentives and decreases with local government's revenue incentives. In particular, spatial and temporal variation in the One-Child Policy may be affected by the local fertility rate, which, in turn, may correlate with the incidence of twins. To test this possibility, we regress future policy fines on prior twin birthrates and see if the latter has predictive power on 
the former. If the association is significant, then the endogeneity problem is worthy of concern. More specifically, in each regression, we use whether the observation is a twin as the key independent variable and the amount of policy fine required in the next year, three years later, or five years later as the dependent variable, respectively. To avoid the potential complexity driven by the zeros assumed for the sample born before 1979, the test is restricted to the sample born after 1979. As shown in Table 4, the rate of twin births does not seem to have any predictive power on the amount of the policy fine over the next one, three, or five years, suggesting that the reverse causality problem may not be serious in this study.

\section{[Table 4 about here]}

Alternatively, we can conduct another set of regressions without using policy fine rates, but exploring only the timing of the One-Child Policy. Following Li et al. (2011), we estimate:

$$
\text { (3) } \text { Twins }_{i j k y}=\beta_{0}+\beta_{2}\left(\text { Policy }_{y \geq 1980} \times \operatorname{Han}_{i}\right)+\theta X_{i j}+{ }_{k y}+\delta_{j}+\gamma_{j} \mathrm{~T}_{j}+\varepsilon_{i}
$$

where Policy P $_{t 1980}$ denotes an indicator of whether birth $i$ was born in 1980 or after, and $\mathrm{Han}_{i}$ is an indicator for Han ethnicity of both parents. The sample used here is the same as the one used to estimate Equations (1) and (2). Polic $y_{y \geq 1980}$ does not solely appear in the equation because its main effect is fully captured by the birth year dummies. The OLS point estimate for $\beta_{2}$ is reported in the final column in Table 3, which also provides strong evidence for the positive association of the One-Child Policy with the incidence of twins. This difference-in-differences (DID) estimate indicates that the One-Child Policy explains over 58 percent $(=0.163 / 0.276)$ of the increase in twins, indicating that our estimates based on the policy fine rate may underestimate the impact of the One-Child Policy. This is reasonable since the 
policy fine is only one of the policy's several means of punishment. Other dimensions, such as administrative punishment not measured by policy fine rates, may be captured in the difference-in-differences estimation. In addition, the fine rate is averaged at the provincial level, which may miss some contributing variation within a province.

The DID estimations assume that the trend in the treatment group (Han ethnicity) without the policy would be similar to that of the control group (minority group). Figure 3 examines this assumption by plotting the twin birthrate by the ethnicity group of the parents against the year of birth. The dashed lines plot LOWESS-smoothed trends with bandwidth 0.8 . The figure shows that the trends in the two groups are almost identical prior to the introduction of the One-Child Policy, indicating the validity of the same trend assumption. ${ }^{17}$

[Figure 3 about here]

\subsection{Heterogeneous Effects}

The actual enforcement of the One-Child Policy is different in urban and rural areas. For example, although urban areas strictly enforce the One-Child Policy, many rural areas allow a couple to have a second child if the first is a girl, namely the "1.5-Child Policy." ${ }^{18}$ This varying

${ }^{17}$ Data before 1970 are not taken into account because of the small sample size. In Figure 3, we do not drop those born after 2001. The larger variance after 2000 is mainly caused by the smaller sample size of the 2005 One-Percent Population Survey.

18 Starting in 2013, China has progressively implemented the One-Single-Child-Parent Policy, which allows a second child if either of the couple is the only child of his or her parents. This policy replaced the prior policy, which allowed a second child only for a couple who both come 
enforcement, together with other potential differences between these two areas, may result in heterogeneous effects. On the one hand, stricter enforcement of the One-Child Policy in urban areas may further distort the incentive of urban people to make twins even at a higher risk of harsh punishment. On the other hand, rural people are generally more poorly educated and rely more on their children or sons for future elderly support, so they have a relatively stronger preference for children or boys, which may in turn cause stronger incentives to obtain more children and more sons. It is an empirical question, therefore, as to how the One-Child Policy increases twin births in urban and rural areas, respectively.

The regression results by residence are reported in Panel A of Table 5. The policy fine is positively correlated with the incidence of twins in both urban and rural areas. The association in rural areas is larger and more significant, indicating the incentive to make twins in rural areas may dominate that in urban areas.

\section{[Table 5 about here]}

Again, due to the 1.5-Child Policy in rural areas, the incentive to have a twin birth may be stronger at different points in time for the two areas: urban people may have to manipulate their birth for the first child while rural people can wait until the second. We examine this heterogeneity by interacting policy fines with birth order dummies in the regressions. As shown in Panel B of Table 5, twins in the second birth are mostly policy relevant and the association is mainly reflected in rural areas, which is consistent with our hypothesis. It is noteworthy here that

from a one-child family. This policy implementation is outside our sample period. 
the second birth here may not be the real second birth due to fake twins reporting. As discussed later, the parents possibly report the second birth child and the third birth child together as twins, and then these twins are observed as second births.

\section{Mechanisms: Reporting Fake Twins and/or Taking Fertility Drugs}

The results above suggest that the One-Child Policy increases twin births in China and the economic magnitude is large. However, little has been done yet to open the "black box" of how people can make twins intentionally to bypass the regulations. People may either report single children as twins ex post or take fertility drugs ex ante to raise the probability of multiple children in a single birth. Although there has been some anecdotal evidence on each of these strategies, no previous research has tried to identify or disentangle either one. In this section, we try to do so by examining the birth gap between first two observed births and the height difference of twins, respectively.

\subsection{Birth Gap between First Two Observed Births}

If an elder child is registered with a younger one as twins, the birthdate of the reported twins should be determined by the younger one, since the parents have to wait until both children are born. If the fake twins are reported to be born as the observed second births, as is more likely in rural areas, there should be a longer birth gap between the first two observed births because the birth gap between the first observed birth and the observed second birth is actually the birth gap between first observed birth and the actual third birth. If the parents plan to bear twins by taking 
fertility drugs, however, there is no reason why they would give the delivery later than normal. Their twins are real twins biologically. In this part, we examine whether the birth gap between the first two observed deliveries is associated with a twin birth and whether the One-Child Policy reinforces this association. ${ }^{19}$ We restrict the sample to the second observed births and conduct the following difference-in-differences regressions:

(4) Birth Gap Bap $_{i}=\beta_{0}\left(\right.$ Policy $_{y \geq 1980} \times$ Twins $\left._{i}\right)+\beta_{3}^{\prime}$ wwins $_{i}+\theta \mathrm{X}_{i}^{\prime}+\delta_{k y}+\delta_{j}+\gamma_{j} \mathrm{~T}_{j}+\varepsilon_{i}$

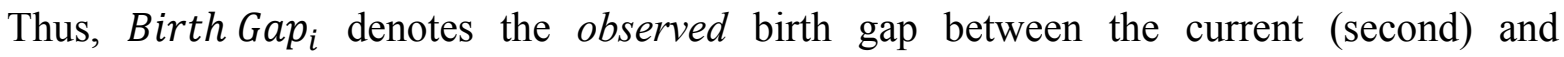
previous (first) delivery for birth $i$, the current (second) observed birth. Twins ${ }_{i}$ denotes whether the current birth of the same parents for birth $i$ is twin birth or not, which captures the potential difference, if any, in birth gap between single births and twin births driven by factors other than the One-Child Policy. The coefficient, $\beta_{3}$, on the interaction term is of central interest because it reflects how much additional length of time is needed to give birth to twins than to a single child after the One-Child Policy. If there are reported fake twins in the observed second births after the One-Child Policy, we should expect the estimated coefficients for $\beta_{3}$ positive because the birth gap between first and second observed births would be lengthened by fake twins reporting.

The covariates $\delta_{k y}, \delta_{j}$ and $\mathrm{T}_{j}$ have the same definitions as before. A new set of other covariates, denoted by $X_{i}^{\prime}$, includes dummies for residence type (urban or rural), parents' ethnicity (both Han or either a minority), mother's education level, and mother's age at first

19 It is possible that the parents make twins in the first observed birth. But we do not consider this case here for two reasons. First, it is not eligible to calculate the birth gap since there is no previous observed birth. Second, the results in Table 5 suggest they are the most policy relevant. 
childbirth. Similar to Equation (3), Policy $y_{y \geq 1980}$ does not solely appear in the equation because its main effect is fully captured by the birth year dummies.

Table 6 reports the OLS estimates for $\beta_{3}$ and $\beta_{3}^{\prime}$ in different samples. For the full sample (column 1), we obtain a positive and significant estimate for $\beta_{3}$, showing that twin births require more time to achieve than single-child births do after the One-Child Policy is introduced. The difference in the birth gap is 0.08 years longer after the One-Child Policy, providing suggestive evidence that parents may report fake twins under the pressure of the One-Child Policy, according to the logic discussed above. The next two columns provide results for Han ethnicity and minorities, respectively. The significant estimates only appear in Han ethnicity, implying that the incentive to have fake twins is larger among Han people, who face stricter regulations.

\subsection{Height Difference between Twins and the One-Child Policy}

Obviously, fake twins should be more different biologically than real twins regardless of their gender composition. Less obviously, the difference in man-made real twins (resulting from fertility drugs) should vary across the gender composition of twins. We show this based on two facts in the medical literature: (a) fertility drug use only results in more dizygotic (different eggs) twins and (b) same-gender dizygotic twins are more different than monozygotic (same eggs) twins (Fischbein 1977; Smith et al. 1973). Because of space constraints, the detailed derivations are relegated to the Appendix. We summarize here only the basic results from the derivation: $(a)$ if the One-Child Policy is not relevant for twin births, the height difference between twins should be uncorrelated with the policy; $(b)$ if the One-Child Policy leads to more fertility drug use 
rather than reporting fake twins, we are likely to see a larger height difference only among same-gender twins under the One-Child Policy; and $(c)$ if there are any reported fake twins, a larger height difference is expected among both same-gender and different-gender twins.

Therefore, we can use height differences of the two children in same-gender twins and mixed-gender twins to test whether they are fake or man-made real twins. If we find the height difference between same-gender twins increases with the policy fines and not so between mixed-gender twins, the increase in twin births is more likely to come from man-made real twins, e.g., those born by taking fertility drugs. If we find that the height difference between mixed-gender twins increases with the policy fines, these are most likely to be fake twins.

For this analysis, we turn to the China Health and Nutrition Survey (CHNS), as it provides data on the heights of children. ${ }^{20}$ As before, twins are defined as children younger than 18 years old with exactly the same birth year and birth month within the same household. We define the height difference of each pair as the difference between the taller and the shorter one. Considering that the height gap may change as the children grow up, we also introduce another measure, the ratio of the height gap to the mean height of the pair (Gap/Mean). We match the twin sample with the fines data and drop those born after 2001, as we did for the census sample.

${ }^{20}$ The China Health and Nutrition Survey includes 26,000 individuals in nine provinces that contain approximately 56 percent of the population of Mainland China. The nine provinces vary substantially in geography, economic development, public resources, and health indicators. Data collection began in 1989 and has been implemented every two to four years since then (Jones-Smith and Popkin 2010). 
After all these restrictions, we have 72 pairs in total, among whom 53 are of the same gender and the rest are of different gender. Table 7 reports the summary statistics for the height gap and the Gap/Mean ratio. The mean height gap is 2.2 centimeters and the Gap/Mean ratio is 1.75 percent. As expected, different-gender twins have much larger difference in height than same-gender twins (4.65 versus $1.30 \mathrm{~cm})$.

\section{[Table 7 about here]}

To estimate the relationship between height difference and the One-Child Policy, we conduct the following estimation:

$$
\text { (5) } H D_{i j y k}=\alpha+\beta_{4} \text { Fine }_{j y m}+\rho Z_{i}+\delta_{y}+\delta_{j}+\delta_{k}+\gamma_{j} \mathrm{~T}_{j}+e_{i}
$$

where the dependent variable, $H D_{i j y k}$ denotes the height difference within twin pair $i$ in province $j$ born in year $y$ of wave $k$. It can be either the height gap or the Gap/Mean ratio, as defined above. The coefficient $\beta_{4}$ gives the association between the policy fines and the height difference between twins. We control for a full set of covariates, $Z_{i}$, that are potentially correlated with the height difference, including indicator variables such as whether they are same-gender twins, urban residence, whether the boy is taller if the pair is different genders, average height of pair $i$, mother's age at childbirth, and age and age squared of the twins. Because of the small sample size, we combine the birth year into four groups (every five years as one group), $\delta_{y}$, to capture the birth year effects. Province dummies and province-specific time trends are also controlled for.

Panel A in Table 8 reports the estimates of Equation (5) and some of its extensions, with standard errors clustered at provincial levels. The first column shows that increasing the fine by 
one year's income is associated with an increase in the height gap of twins by 1.8 centimeters, suggesting that couples may have employed methods to make twins (either by taking drugs or false reporting). We then add interactions of the fines variable with the indicator variable of same-gender as well as that of different-gender twins in the same regression to identify the impact of the One-Child Policy on the height difference of the two types of twins. As shown in column 2 , the policy fines are significantly and positively associated with height differences for both types of twins. Columns 3 and 4 use the Gap/Mean ratio as the dependent variable and the results are similar. Altogether the results in this panel provide supportive evidence on the fake twins hypothesis.

[Table 8 about here]

Since the CHNS is a panel data set and the same twins may be surveyed in different waves, the height difference between the same two children may change over time as they may be affected by different environmental factors throughout their lives. To avoid using the same pair of twins in different waves, we keep observations of only the latest wave for each pair and run the same regressions as above. Panel B in Table 8 reports the estimates for the key variables and the results represent the same pattern, with coefficients of larger magnitude than those in Panel A.

\section{Conclusions}

Based on census data from 1982, 1990, and 2000 and the 2005 One-Percent Population Survey, this paper documents that the twin birthrate in China has more than doubled (from 3.5 to 7.5 per 
thousand births) from the late 1960s to the early 2000s. Although a similar phenomenon also exists in other countries, such as the United States, China may be a special case because of its One-Child Policy. For those who prefer more children or those with a strong preference for boys, the birth of twins is favorable because individuals would be able to have more children, as well as have a higher probability of having a boy, without violating the laws and regulations. Given such a strong incentive, individuals are likely to take actions to increase the probability of giving birth to twins, which may include taking fertility drugs or hiding older children and registering them with younger ones as twins.

This paper aims to answer the question whether the One-Child Policy is associated with the incidence of twins and, if so, how. Above all, through matching census data with the amount of the One-Child Policy regulatory fines by province and year, we find that an increase in policy fines by one year's income is associated with an increase in twin births by approximately 0.07 per thousand births. The estimates in our preferred model indicate that at least one-third of the increase in twins since the 1970s can be explained by the One-Child Policy. The results are robust to different model specifications. We then examine the heterogeneous effects by residence and find that the impact of the policy is larger in rural areas, where the policy raises the twin birthrate mainly for second births. These results indicate that twins may not be randomly distributed throughout the population.

In addition, we further explore the ways in which the increase in twins happens. Using a difference-in-differences identification strategy, we find that after the One-Child Policy was put into effect, the birth gap between the first two observed births is 0.08 years longer when the 
second observed birth is a twin than when it is not. This result is more consistent with the hypothesis that couples report single children as twins after the One-Child Policy. Furthermore, using CHNS data, we show that height difference between twins is positively associated with policy fines and that the association exists in both same- and different-gender twins. These findings support the hypothesis that the One-Child Policy has incentivized people to have twins by reporting non-twin children as twins. However, it is important to note that our results do not rule out the possibility that couples may take fertility drugs intentionally to make twins.

This is the first study to examine people's behavior response against the One-Child Policy by investigating the policy's implications for twin births. Our estimates indicate a sizeable behavioral response from Chinese couples, which motivates future studies to examine the individual behavior responses toward other public policies and to calculate the associated welfare gain or loss in this largest developing country since behavioral response is usually related to social welfare (Hendren 2013). This study also helps to understand the context and background of studies that use data on twins in China. Since twin births can be made by couples intentionally to bypass the One-Child Policy, the distribution of reported twins in China may not be random. However, our results also imply that non-randomly distributed or policy-relevant twins can be screened out by carefully examining the observed characteristics of the twins, such as height, which also backs up the results of other studies along this line. 


\section{References}

Angrist, J. D., and W. N. Evans. 1998. "Children and Their Parents' Labor Supply: Evidence from Exogenous Variation in Family Size.” American Economic Review, 450-77.

Angrist, J., V. Lavy, and A. Schlosser. 2010. "Multiple Experiments for the Causal Link between the Quantity and Quality of Children.” Journal of Labor Economics 28(4): 773-824.

Ashenfelter, O., \& Kruger, A. 1994. Estimates of the Economic Return to Schooling from a New Sample of Twins. The American Economic Review, 84(5), 1157-1173.

Ashenfelter, O., and C. Rouse. 1998. "Income, Schooling, and Ability: Evidence from a New Sample of Identical Twins. The Quarterly Journal of Economics 113(1): 253-84.

Banister, J. 1987. China's Changing Population. Stanford, California: Stanford University Press.

Behrman, J. R., and M. R. Rosenzweig. 2002. "Does Increasing Women's Schooling Raise the Schooling of the Next Generation?" American Economic Review: 323-34.

Black, S. E., P. J. Devereux, and K. G. Salvanes. 2007. "From the Cradle to the Labor Market? The Effect of Birth Weight on Adult Outcomes.” The Quarterly Journal of Economics 122(1): 409-39.

Bortolus, R., F. Parazzini, L. Chatenoud, G. Benzi, M. M. Bianchi, and A. Marini. 1999. "The Epidemiology of Multiple Births.” Human Reproduction Update 5(2): 179-87.

Chew, S. H., J. Heckman, J. Yi, J. Zhang, and S. Zhong. 2010. "Education and Preferences: Experimental Evidence from Chinese Adult Twins.” Education (1/13).

Croll, E., D. Davin, et al. (eds.). 1985. China's One Child Family Policy. London: Macmillan. 
Ebenstein, A. 2010. "The "Missing Girls" of China and the Unintended Consequences of the One Child Policy." Journal of Human Resources 45(1): 87-115.

Fischbein, S. 1977. "Intra-Pair Similarity in Physical Growth of Monozygotic and of Dizygotic Twins during Puberty." Annals of Human Biology 4(5): 417-30.

Greenlaugh, S. 1986. "Shifts in China's Population Policy, 1984-1986: Views from the Central, Provincial, and Local Levels.” Population and Development Review 12(3): 493515.

Greenhalgh, S., and J. Bongaarts. 1992. Fertility Policy in China: Future Options (pp. 401-419). Springer US.

Hendren, N. 2013. "The Policy Elasticity.” NBER Working Paper No. 19177, National Bureau of Economic Research, Cambridge, Mass.

Jones-Smith, J. C., and B. M. Popkin. 2010. "Understanding Community Context and Adult Health Changes in China: Development of an Urbanicity Scale." Social Science \& Medicine 71(8): 1436-46.

Li, H., Zhang, J., \& Zhu, Y. 2008. The quantity-quality trade-off of children in a developing country: Identification using Chinese twins. Demography, 45(1), 223-243.

Li, H., P. W. Liu, J. Zhang, and N. Ma. 2007. "Economic Returns to Communist Party Membership: Evidence from Urban Chinese Twins.” The Economic Journal 117(523): 150420.

Li, H., J. Yi, and J. Zhang. 2011. "Estimating the Effect of the One-Child Policy on the Sex Ratio Imbalance in China: Identification Based on the 
Difference-in-Differences.” Demography 48(4): 1535-57.

Li, H., P. W. Liu, and J. Zhang. 2012. "Estimating Returns to Education Using Twins in Urban China." Journal of Development Economics 97(2): 494-504.

Li, H., Liu, P. W., Ye, M., \& Zhang, J. (2011). Does money buy happiness? Evidence from twins in urban China. Manuscript, Harvard University.

Martin, J. A., B. E. Hamilton, and M. J. Osterman. 2012. Three Decades of Twin Births in the United States, 1980-2009. US Department of Health and Human Services, Centers for Disease Control and Prevention, National Center for Health Statistics.

Oleszczuk, J. J., D. M. Keith, L. G. Keith, and W. F. Rayburn. 1999. "Projections of Population-Based Twinning Rates through the Year 2100." The Journal of Reproductive Medicine 44(11): 913-21.

Ponczek, V., and A. P. Souza. 2012. "New Evidence of the Causal Effect of Family Size on Child Quality in a Developing Country." Journal of Human Resources 47(1): 64-106.

Qian, N. 2009. "Quantity-Quality and the One Child Policy: The Only-Child Disadvantage in School Enrollment in Rural China.” NBER Working Paper No. 14973, National Bureau of Economic Research, Cambridge, Mass.

Rosenzweig, M. R., and K. I. Wolpin. 1980a. "Life-Cycle Labor Supply and Fertility: Causal Inferences from Household Models.” Journal of Political Economy 88(2): 328-48.

Rosenzweig, M. R., and K. I. Wolpin. 1980b. "Testing the Quantity-Quality Fertility Model: The Use of Twins as a Natural Experiment." Econometrica: Journal of the Econometric Society 48(1): 227. 
Rosenzweig, M. R., \& Wolpin, K. I. 2000. Natural" Natural Experiments. Journal of Economic Literature, 38(4), 827-874.

Rosenzweig, M. R., and J. Zhang. 2009. “Do Population Control Policies Induce More Human Capital Investment? Twins, Birth Weight and China's "One-Child” Policy." The Review of Economic Studies 76(3): 1149-74.

Rosenzweig, M. R., and J. Zhang. 2012. "Economic Growth, Comparative Advantage, and Gender Differences in Schooling Outcomes: Evidence from the Birthweight Differences of Chinese Twins.” Discussion Paper No. 1008, Economic Growth Center. Yale University

Rossing, M. A., J. R. Daling, N. S. Weiss, D. E. Moore, and S. G. Self. 1994. "Ovarian Tumors in a Cohort of Infertile Women.” New England Journal of Medicine 331(12): 771-76.

Royer, H. 2009. "Separated at Girth: US Twin Estimates of the Effects of Birth Weight." American Economic Journal: Applied Economics 1(1): 49-85.

Segal, N. L. 1999. Entwined lives: Twins and What They Tell Us about Human Behavior. Dutton/Penguin Books.

Segal, Nancy L. 1985. "Monozygotic and Dizygotic Twins: A Comparative Analysis of Mental Ability Profiles." Child Development: 1051-58.

Smith, David M., Walter E. Nance, Ke Won Kang, Joe C. Christian, and C. Conrad Johnston, Jr. 1973. "Genetic Factors in Determining Bone Mass." The Journal of Clinical Investigation 52(11): 2800-08.

Starr, B. 2008. "Ask a Geneticist." Available from Stanford School of Medicine The Tech: http://www. thetech. org/genetics/ask. php. 
Stunkard, A. J., T. T. Foch, and Z. Hrubec. 1986. "A Twin Study of Human Obesity." Jama 256(1): 51-54.

Wang, F. 2012. "Family Planning Policy in China: Measurement and Impact on Fertility."

Wei, S. J., and Zhang, X. 2011. The Competitive Saving Motive: Evidence from Rising Sex Ratios and Savings Rates in China. Journal of Political Economy,119(3), 511-564.

Zhang, J., P. W. Liu, and L. Yung. 2007. "The Cultural Revolution and Returns to Schooling in China: Estimates Based on Twins.” Journal of Development Economics 84(2): 631-39. 
Table 1: Summary statistics

\begin{tabular}{lccc}
\hline \hline & $(1)$ & $(2)$ & $(3)$ \\
Variables & Full sample & $\begin{array}{c}\text { Parents are } \\
\text { Han }\end{array}$ & $\begin{array}{c}\text { Either parent } \\
\text { is minority }\end{array}$ \\
\hline Twins (\%) & 0.58 & 0.59 & 0.44 \\
& $(7.58)$ & $(7.65)$ & $(6.58)$ \\
Rural area (Yes = 1) & 0.73 & 0.72 & 0.81 \\
& $(0.45)$ & $(0.45)$ & $(0.40)$ \\
Both parents Han ethnicity (Yes = 1) & 0.93 & & \\
& $(0.26)$ & & \\
Age & 8.04 & 8.08 & 7.62 \\
& $(4.67)$ & $(4.67)$ & $(4.62)$ \\
Mother's age when giving birth & 23.25 & 23.28 & 22.82 \\
& $(2.97)$ & $(2.95)$ & $(3.18)$ \\
Birth order & & & \\
First & 0.57 & 0.57 & 0.51 \\
Second & $(0.50)$ & $(0.50)$ & $(0.50)$ \\
Third or above & 0.30 & 0.29 & 0.32 \\
Observations & $(0.46)$ & $(0.46)$ & $(0.46)$ \\
\hline \hline
\end{tabular}

Notes: Data source is Census 1982, 1990, 2000 and 2005. Standard deviations in parentheses. The sample is restricted to the births before 2001 . 
Table 2: Twin birthrates for Han and Minorities

\begin{tabular}{lccc}
\hline \hline & $(1)$ & $(2)$ & $(3)$ \\
Parents Ethnicity & Born no later than & Born after & $\begin{array}{c}\text { Difference } \\
(2)-(1)\end{array}$ \\
\hline Han & 1979 & 1979 & 0.276 \\
Either Minority & 0.39 & 0.67 & \\
& $(6.25)$ & $(8.15)$ & 0.075 \\
\hline \hline
\end{tabular}

Notes: Data source is Census 1982, 1990, 2000 and 2005. Standard deviations are in parentheses.

Table 3: Twin birthrates and the One-Child Policy fine rate

\begin{tabular}{|c|c|c|c|c|c|}
\hline & (1) & (2) & (3) & (4) & (5) \\
\hline Sample & Full sample & Parents Han & $\begin{array}{c}\text { Either Parent } \\
\text { Minority }\end{array}$ & Full sample & Full sample \\
\hline Dependent variable & & & Twins & & \\
\hline Policy fine rate & $\begin{array}{l}0.0665^{*} \\
(0.0380)\end{array}$ & $\begin{array}{l}0.0717 * \\
(0.0406)\end{array}$ & $\begin{array}{c}0.0114 \\
(0.0287)\end{array}$ & $\begin{array}{c}0.0212 \\
(0.0175)\end{array}$ & \\
\hline Policy fine rate * Parents Han & & & & $\begin{array}{c}0.0527 * * * \\
(0.0158)\end{array}$ & \\
\hline Born after $1979 *$ Parents Han & & & & & $\begin{array}{l}0.163 * * * \\
(0.0299)\end{array}$ \\
\hline Observations & $5,965,262$ & $5,553,384$ & 411,878 & $5,965,262$ & $5,965,262$ \\
\hline R-squared & 0.001 & 0.001 & 0.001 & 0.001 & 0.001 \\
\hline
\end{tabular}

Notes: Data source is Census 1982. 1990, 2000 and 2005. Robust standard errors in parentheses are clustered in provincial level. ${ }^{* * *} \mathrm{p}<0.01,{ }^{* *} \mathrm{p}<0.05,{ }^{*} \mathrm{p}<0.1$. The One-Child policy fine is measured in years of local household income. Sampling weights are applied. Coefficients should be interpreted as percentage because all dependent variables have been multiplied by 100 . Covariates include residency type, province, birth order, mother's education level, mother giving birth age, year of birth, survey year, and interactions between year of birth and survey year. Parents' ethnicity dummy is controlled for in columns 1,4 and 5 . 
Table 4: One-Child Policy fine predicted by the prior rate of twin births, post-1979

\begin{tabular}{lccc}
\hline \hline \multirow{2}{*}{ Dependent variable } & $(1)$ & $(3)$ & $(5)$ \\
& & \multicolumn{3}{c}{ One-Child Policy Fine } \\
\cline { 2 - 4 } Twins & 1 year later & 3 years later & 5 years later \\
& 0.0102 & 0.00833 & 0.00133 \\
& $(0.00628)$ & $(0.00543)$ & $(0.00656)$ \\
Observations & $4,286,030$ & $4,118,084$ & $3,913,326$ \\
R-squared & 0.752 & 0.775 & 0.800 \\
\hline \hline
\end{tabular}

Notes: Data source is Census 1982. 1990, 2000 and 2005. Robust standard errors in parentheses are all clustered at the provincial level. $* * * \mathrm{p}<0.01, * * \mathrm{p}<0.05, * \mathrm{p}<0.1$. Only post-1979 births are used. Covariates include continuous variables like provincial time trend, and indicator variables, like residency type, parents' ethnicity, province, birth order, mother giving birth age, year of birth, survey year, and interactions between year of birth and survey year.

Table 5: Heterogeneous effects of policy fine on twins birth

\begin{tabular}{|c|c|c|c|}
\hline & $(1)$ & (2) & (3) \\
\hline & \multirow{2}{*}{ Parents Han } & \multicolumn{2}{|c|}{ Subsamples by type of residence } \\
\hline & & Urban & Rural \\
\hline & \multicolumn{3}{|c|}{ Dependent variable is Twins } \\
\hline \multicolumn{4}{|c|}{ Panel A: Policy Fine } \\
\hline Policy fine rate & $\begin{array}{l}0.0717 * \\
(0.0406)\end{array}$ & $\begin{array}{c}0.0591 \\
(0.0407)\end{array}$ & $\begin{array}{l}0.0842 * \\
(0.0413)\end{array}$ \\
\hline \multicolumn{4}{|c|}{ Panel B: Policy Fine interacting with birth order } \\
\hline First & $\begin{array}{c}0.0400 \\
(0.0402)\end{array}$ & $\begin{array}{c}0.0538 \\
(0.0424)\end{array}$ & $\begin{array}{c}0.0341 \\
(0.0400)\end{array}$ \\
\hline Second & $\begin{array}{c}0.151 * * * \\
(0.0471)\end{array}$ & $\begin{array}{c}0.0931 \\
(0.0598)\end{array}$ & $\begin{array}{c}0.167 * * * \\
(0.0462)\end{array}$ \\
\hline Third and above & $\begin{array}{c}0.0718 \\
(0.0468)\end{array}$ & $\begin{array}{c}0.0274 \\
(0.0645)\end{array}$ & $\begin{array}{l}0.0863 * \\
(0.0442)\end{array}$ \\
\hline Observations & $5,553,384$ & $1,394,364$ & $4,159,020$ \\
\hline \multicolumn{4}{|c|}{$\begin{array}{l}\text { Notes: Data source is Census } 1982.1990,2000 \text { and } 2005 \text {. Robust standard errors in parentheses are clustered at the } \\
\text { provincial level. } * * * p<0.01, * * p<0.05, * p<0.1 \text {. The One-Child Policy fine is measred in years of household } \\
\text { income. Sampling weights are applied. Coefficients should be interpreted as percentage because all dependent } \\
\text { variables have been multiplied by } 100 \text {. Covariates include dummies for residency type, parents' ethnicity, province, } \\
\text { birth order, mother giving birth age, year of birth, survey year, and interactions between year of birth and survey } \\
\text { year. }\end{array}$} \\
\hline
\end{tabular}


Table 6: Age gap between first and second birth, twins and the One-Child Policy

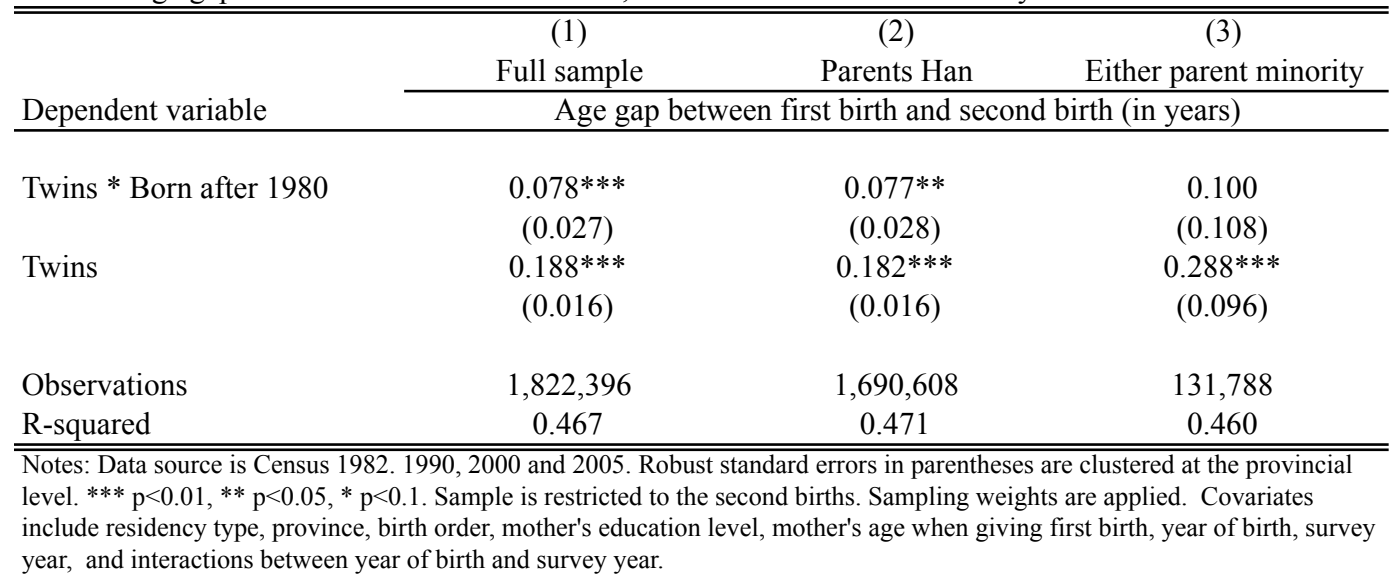

Table 7: Summary statistics in CHNS

\begin{tabular}{|c|c|c|c|}
\hline \multirow[b]{3}{*}{ Variable } & $(1)$ & (2) & (3) \\
\hline & \multirow{2}{*}{ All twins } & \multicolumn{2}{|c|}{ By type of twins } \\
\hline & & Same gender & Different gender \\
\hline \multirow[t]{2}{*}{ Height gap (cm) } & 2.18 & 1.30 & 4.65 \\
\hline & $(2.74)$ & $(1.59)$ & $(3.68)$ \\
\hline \multirow[t]{2}{*}{ Mean of height $(\mathrm{cm})$} & 121.15 & 119.58 & 125.55 \\
\hline & $(27.59)$ & $(28.47)$ & $(25.17)$ \\
\hline \multirow[t]{2}{*}{ Gap/Mean ratio in percent } & 1.75 & 1.02 & 3.78 \\
\hline & $(2.14)$ & $(1.14)$ & $(2.90)$ \\
\hline Observations & 72 & 53 & 19 \\
\hline \multicolumn{4}{|c|}{$\begin{array}{l}\text { Notes: Data source is CHNS. Standard deviations are reported in parentheses. Data source is China Health and } \\
\text { Nutrition Survey. Twins are defined as children (aged below 18) born in the same household within the same month } \\
\text { For each pair of twins, height gap is defined as the height of the taller member minus that of the shorter one. } \\
\text { Gap/Mean ratio is defined as twins' height gap divided by the mean height of the pair, and the values reported are } \\
\text { multiplied by } 100 \text {. }\end{array}$} \\
\hline
\end{tabular}


Table 8: Height difference and One-Child Policy fine

\begin{tabular}{|c|c|c|c|c|}
\hline & (1) & (2) & (3) & (4) \\
\hline Dependent variable & \multicolumn{2}{|c|}{ Height Difference $(\mathrm{cm})$} & \multicolumn{2}{|c|}{ Height Difference/Mean } \\
\hline \multicolumn{5}{|l|}{ Panel A: Full sample } \\
\hline Fine in years of income & $\begin{array}{c}1.834 * * * \\
(0.313)\end{array}$ & & $\begin{array}{r}1.698 * * \\
(0.229)\end{array}$ & \\
\hline \multicolumn{5}{|l|}{ Interactions } \\
\hline Same gender pair \& Fine & & $\begin{array}{c}2.075^{* * *} * \\
(0.380)\end{array}$ & & $\begin{array}{c}1.772 * * * \\
(0.263)\end{array}$ \\
\hline Different gender pair \& Fine & & $\begin{array}{c}0.706^{* *} \\
(0.240)\end{array}$ & & $\begin{array}{c}1.348 * * * \\
(0.252)\end{array}$ \\
\hline Observations & 72 & 72 & 72 & 72 \\
\hline R-squared & 0.631 & 0.640 & 0.631 & 0.632 \\
\hline \multicolumn{5}{|c|}{ Panel B: Only the latest wave is kept } \\
\hline Fine in years of income & $\begin{array}{c}3.284^{* *} \\
(1.079)\end{array}$ & & $\begin{array}{r}2.709^{* *} \\
(0.586)\end{array}$ & \\
\hline Interactions & & $3.368^{*}$ & & $2.585 * *$ \\
\hline \multirow[t]{2}{*}{ Same gender pair \& Fine } & & $(1.565)$ & & $(0.836)$ \\
\hline & & $\begin{array}{c}2.935 \\
(1.946)\end{array}$ & & $\begin{array}{c}3.226^{* *} \\
(1.158)\end{array}$ \\
\hline Observations & 33 & 33 & 33 & 33 \\
\hline R-squared & 0.744 & 0.745 & 0.765 & 0.768 \\
\hline $\begin{array}{l}\text { Notes: Data source is CHNS. Standa } \\
\mathrm{p}<0.05,{ }^{*} \mathrm{p}<0.1 \text {. Data source is } \mathrm{CHN} \\
2001 \text {. Height gap is defined as the he } \\
\text { is defined as twins' height gap divide } \\
\text { pair of twins. Covariates includege a } \\
\text { variables such as whether they are sa } \\
\text { different genders, provinces, year of }\end{array}$ & $\begin{array}{l}\text { Thrors in parent } \\
\text { The twins sam } \\
\text { t of the taller } t \\
y \text { the mean hei } \\
\text { age squared of } \\
\text {-gender twins, } \\
\text { th categories, } s\end{array}$ & $\begin{array}{l}\text { ses are cluster } \\
\text { used in this t } \\
n \text { minus that } \mathrm{x} \\
\text { t of the pair. I } \\
\text { e twins, moth } \\
\text { ban residence } \\
\text { vey year, and }\end{array}$ & $\begin{array}{l}\text { provincial } 1 \\
\text { re those bo1 } \\
\text { horter one, } \\
\text { bservation } \\
\text { e at childbi } \\
\text { her the boy } \\
\text { cial linear }\end{array}$ & $\begin{array}{l}\text { *** }<<0.01, * * \\
\text { ween } 1979 \text { and } \\
\text { zap/height ratio } \\
\text { lved from one } \\
\text { d indicator } \\
\text { ler if the pair is } \\
\text { rend. }\end{array}$ \\
\hline
\end{tabular}




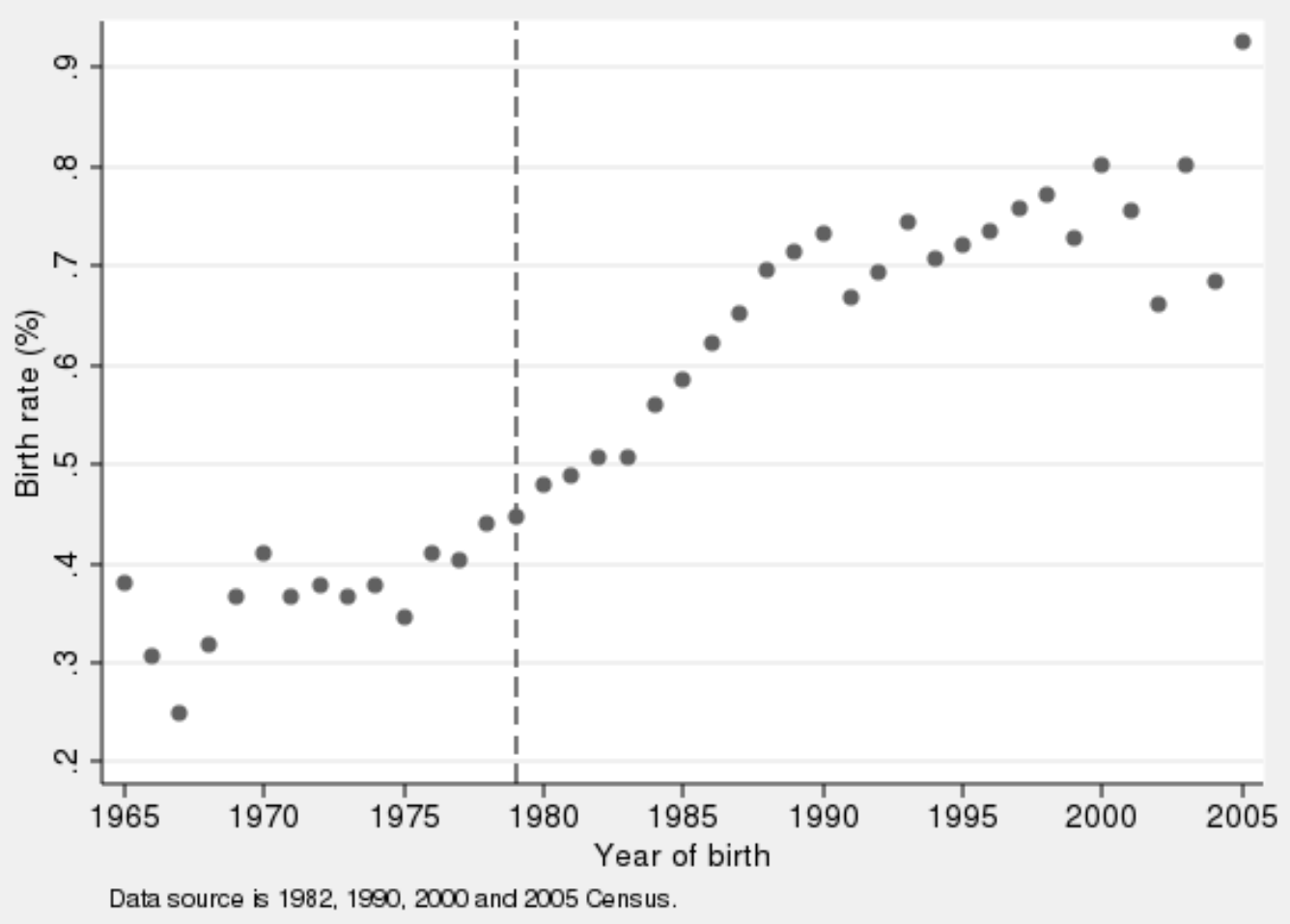

Figure 1 Twins Rates Against Year of Birth 


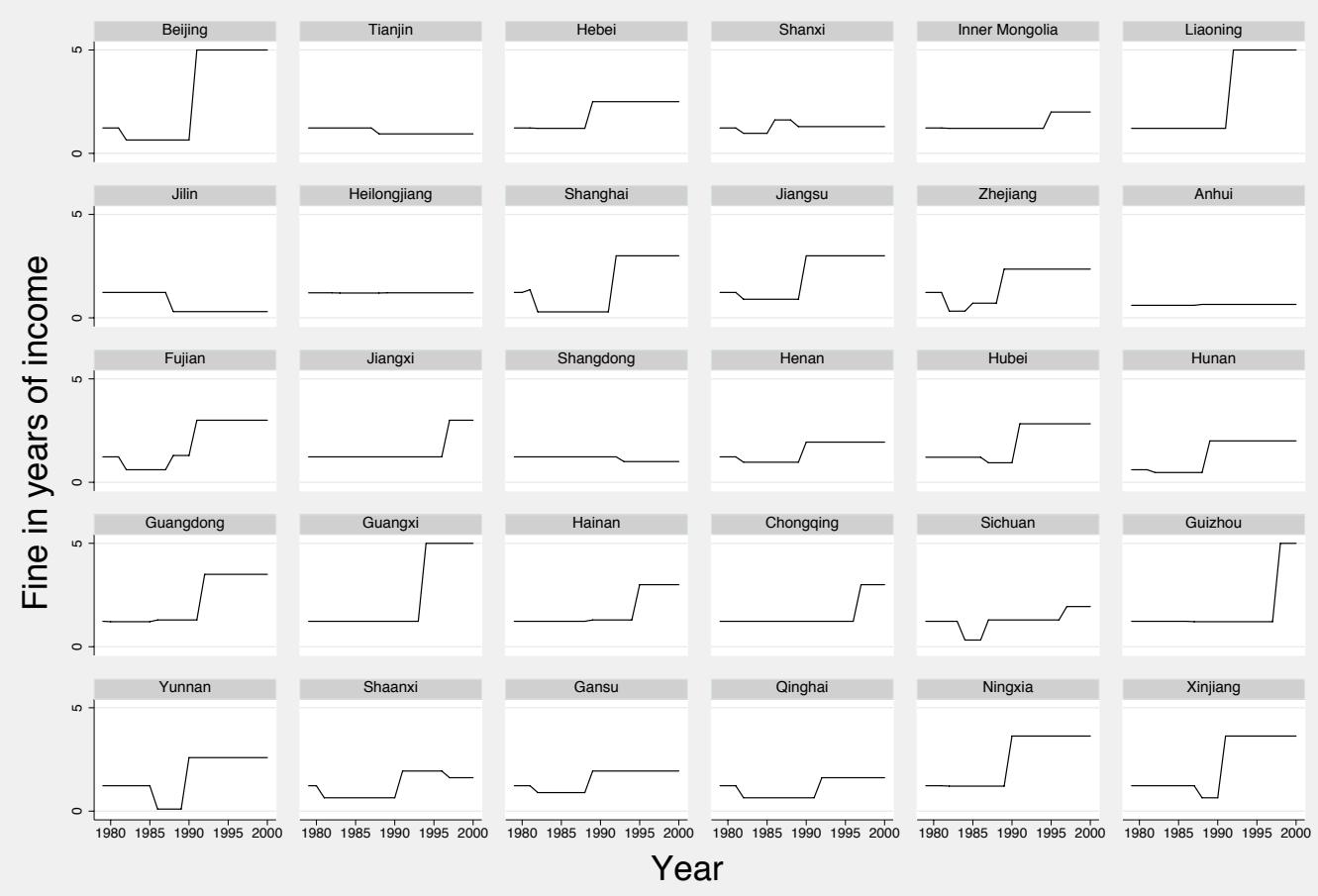

Note: Data source is Ebenstein (2010).

Figure 2 One-Child Policy Regulatory Fines, by Province 


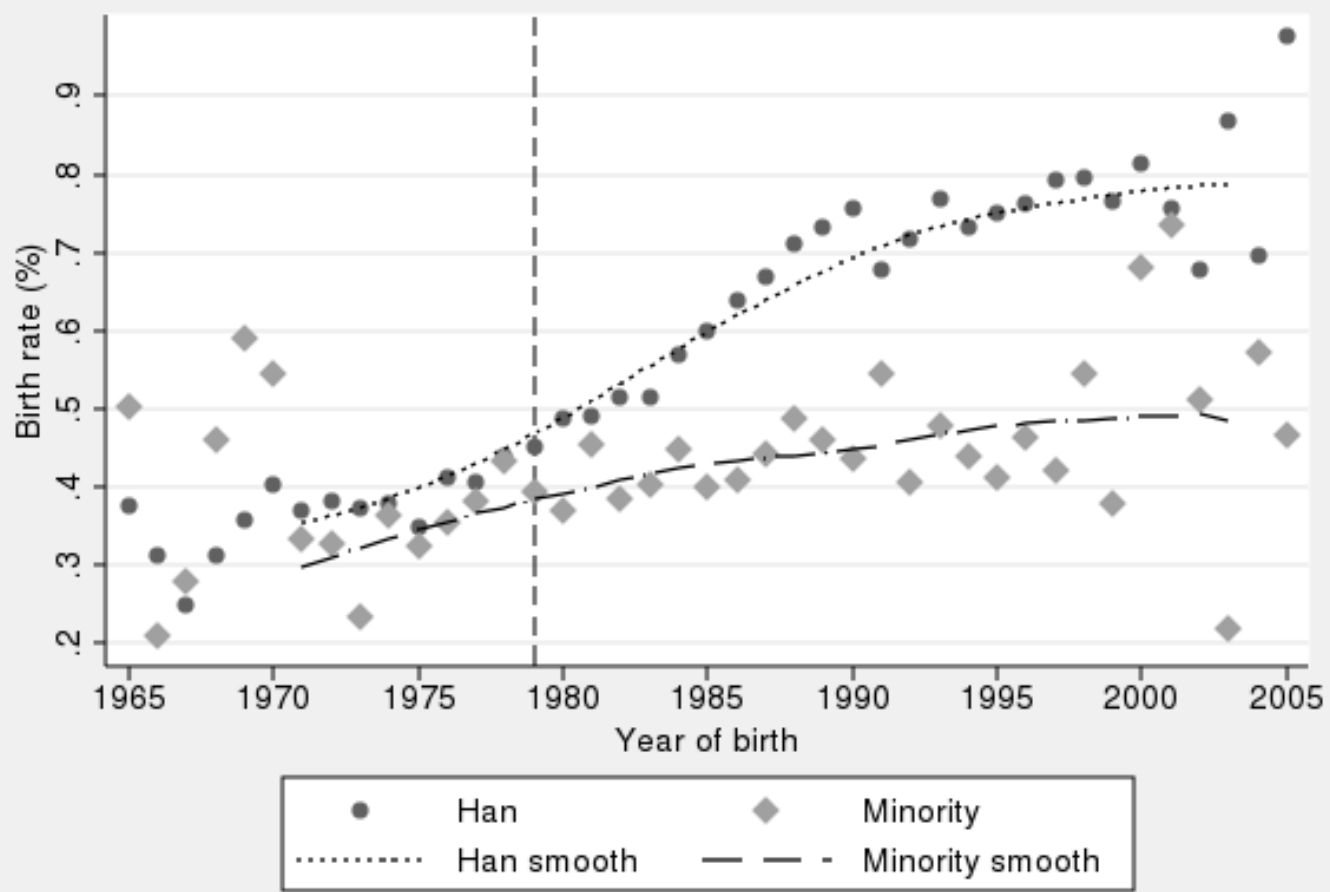

Data source is 1982, 1990, 2000 and 2005 Census.

Figure 3 Twins Rates Against Year of Birth, by Parents' Ethnicity 


\section{Appendix: The One-Child Policy and Height Differences between Twins}

Two different hypotheses, the real "man-made" twins and the fake twins, are derived. For simplicity, we only use financial penalties (fines) to measure the One-Child Policy and assume it equals one when a financial penalty policy is established in the local province and zero if otherwise.

\section{A.1 Real "Man-Made” Twins Hypothesis}

The man-made twins hypothesis indicates that individuals are motivated to use technology, such as fertility drugs, to give birth to twins, under the One-Child Policy. Taking fertility drugs should be reasonable, but embryo technologies did not appear in China until the late 1990s. The mechanisms of fertility drugs are usually to induce ovulation and the drugs are usually used to treat infertility (Rosing et al. 1994). When normal women take them, the possibility of multiple ovulations is increased; thus, they are more likely to have twins (Bortolus. Whittmore 1992; Starr 2008) Although these drugs are classified as prescription medicines, it is still possible for individuals to purchase them in certain private hospitals or to get prescriptions from certain doctors by bribing the doctors, lying and so on.

Under the man-made twins hypothesis, individuals are more likely to take fertility drugs $($ Take $=1)$ to have more children and avoid being punished under the One-Child Policy, that is, $\operatorname{Pr}($ Take $=1 \mid$ Fine $=1)>\operatorname{Pr}($ Take $=1 \mid$ Fine $=0)$. According to the medical literature and stylized facts, we know that taking certain fertility drugs or using technologies increases the probability of giving birth to twins: $\operatorname{Pr}($ Twins $=1 \mid$ Take $=1)>\operatorname{Pr}($ Twins $=1 \mid$ Take $=0)$. 
We also assume that, conditional on individuals' behaviors (Take), giving birth to twins is independent of the One-Child Policy. In addition, the biological results of fertility drugs or embryo technologies are to develop multiple zygotes in the uterus at the same time, rather than to stimulate a single fertilized egg in the mother's body to divide into two or more embryos. Thus, these actions only raise the probability of dizygotic (DZ) twins rather than that of monozygotic (MZ) twins, that is,

$$
\begin{aligned}
& \operatorname{Pr}(D Z=1 \mid \text { Take }=1)>\operatorname{Pr}(D Z=1 \mid \text { Take }=0) \text { and } \\
& \operatorname{Pr}(M Z=1 \mid \text { Take }=1)=\operatorname{Pr}(M Z=1 \mid \text { Take }=0) .
\end{aligned}
$$

According to the medical literature, MZ twins are genetically nearly identical and they are always of the same gender unless there has been a mutation during development. But it is possible that same-gender twins are DZ. Certain characteristics of MZ twins become more alike as twins age, such as IQ and personality (Segal 1999). DZ twins, however, like any other siblings, have an extremely small chance of having the same chromosome profile. DZ twins may look very different from each other and may be of different genders or the same gender. The above also holds for brothers and sisters from the same parents, meaning that DZ twins can be viewed as siblings who happen to be of the same age. Therefore, we have $\operatorname{Pr}(D Z=1 \mid D G=1)=$ $1, \operatorname{Pr}(S G=1 \mid M Z=1)=1,0<\operatorname{Pr}(\mathrm{DZ}=1 \mid \mathrm{SG})<1$, and $0<\operatorname{Pr}(\mathrm{MZ}=1 \mid \mathrm{SG})<1$.

An established strand of literature has proved that DZ twins tend to have more differences than MZ ones as they grow up because of genetic disparity, including height (Fischbein 1977; Smith et al. 1973), weight (Stunkard et al. 1986), mental ability profiles (Segal 1985), bone mass (Smith et al. 1973), and so on. Specifically, Fischbein (1977) found that MZ twins have a 
significantly higher concordance in height than for DZ pairs during puberty, for both boys and girls, and yearly height increments are also more similar for $\mathrm{MZ}$ pairs, indicating that the height spurt occurs more simultaneously for MZ twins in comparison to DZ twins. Thus, we presume that the height difference (HD) within a DZ (same-gender) pair should be larger than that of an $\mathrm{MZ}$ pair if other factors are equalized. Thus, $E(H D \mid S G=1, D Z=1)>E(H D \mid S G=1, M Z=$ 1).

In addition, we assume that the actions people may take do not influence twins' height differences conditional on the twins' type (MZ or DZ). Based on the facts or assumptions above, it can be shown that

(1) $E($ HD $\mid$ Fine $=1$, Twins =1) $>E($ HD $\mid$ Fine $=0$, Twins =1),

(2) $E(H D \mid$ Fine $=1, S G=1)>E(H D \mid$ Fine $=0, S G=1)$, and

(3) $E(H D \mid$ Fine $=1, D G=1)=E(H D \mid$ Fine $=0, D G=1)$.

Equation (1) tells us that twins' height differences would be larger under the One-Child Policy, as there will be more DZ twins due to the methods the individuals take in response to the One-Child Policy. This response will increase DZ proportions in same-gender twins, and thus the height difference in this group will become larger (Equation 2). However, different-gender twins' height differences will not change because they themselves are DZ (Equation 3). Because we do not know whether a woman took fertility drugs or not, equations (1) through (3) are important because height difference, One-Child Policy fine, and twins' gender composition are all observables and thus allow for empirical tests.

\section{A.2 Reporting Fake Twins Hypothesis}


The fake twins hypothesis means that parents report non-twin children as twins in order to avoid punishment under the One-Child Policy. This was somehow feasible under some special circumstances earlier in China. First, many pregnant women gave birth at home in the 1980s and the population administration would not notice until parents reported their infants, although they were required to do so. Second, birth certificates were not launched until 1997 and children's birthdates were easy to revise before that. Third, children — especially siblings—look alike, in particular when the age difference is not large. Although parents will face harsher punishment once they are found to have reported fake twins, many parents may still choose to do so because of strong preferences for children or boys.

Under the fake twins hypothesis, the One-Child Policy stimulates people's incentives to report fake twins, that is, $\operatorname{Pr}($ Twins $* \mid$ Fine $=1)>\operatorname{Pr}($ Twins $* \mid$ Fine $=0)$, in which $T$ wins $*$ denotes the observed twins, including real ones and fake ones. For real twins (Twins), we assume all of them are reported, that is, $\operatorname{Pr}($ Twins $* \mid$ Twins $)=1$.

The most important difference between fake twins and true twins is the age. For simplicity, we only consider the factors of age and do not take into account the gender factor in height differences in different-gender twins here because all the children are very young. Because of the age difference, the height difference within fake twins would be larger, so $E(H D \mid$ Twins $*)>E(H D \mid$ Twins $)$ if $\operatorname{Pr}($ Twins $\mid$ Twins $*)<1$.

The condition $\operatorname{Pr}($ Twins $\mid$ Twins $*)<1$ ensures that fake twins do exist. If parents have a strong preference for children and do not care about the gender, then the gender composition of fake twins should be random, so that height differences in both (observed) same-gender twins and 
different-gender ones should be larger. However, if parents have a strong boy preference, they are more likely to construct different-gender twins because they have less incentive to make fake twins when they had a boy already. No matter which case it is, under the fake twins hypothesis, we must have

(4) $E(H D \mid$ Twins $*$ Fine $=1)>E(H D \mid$ Twins $*$,Fine $=0)$ and

(5) $E\left(H D \mid D G^{*}\right.$,Fine $\left.=1\right)>E\left(H D \mid D G^{*}\right.$, Fine $\left.=0\right)$,

in which $D G^{*}$ denotes the observed different-gender twins. As before, equations (4) and (5) are based on observables, so they can be tested in empirical analysis.

In summary, from the derivations above, we reach the following testable results: a) if the One-Child Policy is not relevant for twin births, the height difference between twins should be uncorrelated with the policy; b) if the One-Child Policy leads to more fertility drug use rather than reporting fake twins, we are likely to see a larger height difference only among same-sex twins under the One-Child Policy; and c) if there are any reported fake twins, a larger height difference is expected among both same-sex and different-sex twins. 